\title{
Determination of Factors Affecting Technical Efficiency in Smallholders' Dairy Production in Rwanda:Case of Nyanza District
}

\author{
Straton HABUMUGISHA ${ }^{1}$ David Mwehia Mburu ${ }^{2} \quad$ Patrick Mulyungi $^{2}$ \\ 1.Postgraduate student, Jomo Kenyatta University of Agriculture and Technology, Kg 281 ST, Rwanda \\ 2. Senior Lecturer, Jomo Kenyatta University of Agriculture and Technology, Kenyatta Avenue P.O. Box 62000 \\ - 00200 Nairobi, Kenya
}

\begin{abstract}
Dairy value chain has an important role in income generation and provision of employment. The latest trends in demand for dairy products is progressively exceeding the supply in the Rwanda and in Nyanza district particularly; this constitute a genesis of discussion and analysis of dairy production situation. Smallholder dairy farming is practiced in Rwanda aiming at generating income and nutrients in households; however, the efficiency in smallholder dairy farming is highly disputed. This study examined factors affecting technical efficiency of smallholder dairy farmers in Nyanza District with estimation of the marginal gross profit of smallholder dairy production. Stratified random sampling was adopted to determine the respondents. Primary data were drawn from 110 smallholder farmers using structured questionnaires. Non-parametric approach, Gross margin and Stochastic Frontier were employed. The results revealed that socio-economic factors and institutional factors directly affects technical efficiency of smallholder dairy production. The study will help the government and smallholder dairy farmers in organizing themselves in groups for bulk purchases of inputs during high season this will end up reducing unnecessary cost of transporting and price increase of inputs during low season hence increasing milk production
\end{abstract}

Key words: smallholder dairy farming, stochastic frontier, Technical efficiency, Nyanza District, Rwanda

DOI: $10.7176 /$ EJBM/12-8-03

Publication date:March $31^{\text {st }} 2020$

\section{Introduction}

\subsection{Background of the Study}

In Rwanda agriculture is the main economic activity practiced by over $80 \%$ of the country labour force (NISR, 2015). The dairy subsector of agriculture sector is the largest segment of the livestock sector contributing $15 \%$ to the Agricultural Gross Domestic Product (AGDP) and 6\% to the country's GDP (MINAGRI, 2015). In Rwanda, the sub-sector has been an integral part of the production systems and it has high potential for food security and livelihoods (FAO, 2015). In the last two decades the cattle size has increased from 0.6 million to 1.3 million $45 \%$ of which being local breed, 33\% diary cross-breeds and 22\% diary pure breed (MINAGRI, 2014). Rwanda now produces 600,000 metric tons of milk annually, an increase of more than 300 percent in less than a decade.

\subsection{Problem Statement}

Despite its potential in production, dairy sub-sector in Rwanda is constrained by several factors. Although the question of efficiency in the use of farm resources has a considerable interest to researchers. In the country it is estimated that milk production ranges between 0.7 and 3.2 litres per cow which is equivalent to annual yield of 258 litres per cow; in comparison production in Rwanda is lower below neighbouring countries such as Kenya with milk production ranging 2.2 to 7.7 litres per cow equivalent to annual yield of 640 litres per cow (Technoserve, 2008). Several studies have been conducted to explain low milk production in Rwanda. A study of Lakes (2014) found that level of milk and milk products are constrained by multitude factors mainly being lack of quality fodder coupled with non-use of concrete supplements and poor genetic potential of the indigenous cattle. A study of Gelan et al. (2011) found that only small proportion of smallholder dairy farmers purchase inputs such as feed supplements, veterinary medicine and various equipment required which result into low usage of inputs. Despite several researches conducted on various facets of Rwanda dairy sub-sector, there is absence of study conducted in dairy sub-sector to look on production efficiency to determine primarily the ability of dairy smallholder farmers to produce on their maximum and if dairy smallholder farmers have the ability to produce a given level of output using the cost minimizing inputs ratio. This constitutes a gap to the Government policy such as zero grazing in cattle farming and the increase in number of cows owned by smallholder farmers through GIRINKA. To fill this knowledge gap this study analysed factors affecting technical efficiency of the smallholder dairy production. The findings will enable policy makers to understand areas which should be improved so as to increase efficiency of dairy sub-sector. 


\subsection{General Objective}

The general objective of this study was to analyse factors influencing Technical Efficiency(TE) of smallholder dairy production in Nyanza district.

\subsection{Specific Objectives}

i. To determine socio-economic factors affecting technical efficiency of smallholder dairy production.

ii. To describe the institutional factors affecting technical efficiency of smallholders dairy production

iii. $\quad$ To analyse smallholder dairy farmers technical efficiency.

\subsection{Study Area}

This research included the district of Nyanza District; once of seven districts composing the Southern province of Rwanda. Geographically, the district is located at $2^{\circ} 30^{\prime} \mathrm{S} 29^{\circ} 30^{\prime} \mathrm{E}$, an area of $672 \mathrm{~km}^{2}$ and has population of 323 719 in the 2012 census. The district lies between Muhanga and Huye districts, straddling the main Kigali to Bujumbura road. Nyanza district is experiences annual temperature ranging between $18^{\circ} \mathrm{C}$ and $19^{\circ} \mathrm{C}$ with annual precipitation of $1234 \mathrm{~mm} / \mathrm{an}$; agricultural reports that the district hosts more than 345000 cows including both indigenous and modern breeds.

\section{Methodology}

\subsection{Research Design and Sampling Procedures}

The research was designed with adoption of cross-sectional type and the data collection was conducted one point on condensed time allowing to give a full picture of smallholder dairy farmers' performance in terms of socioeconomic factors, institutional factors, profitability and technical efficiency in Nyanza district; the district was chosen because it has a significant number of dairy producers in Rwanda. This was followed by sampling of 6 sectors in which respondent were taken from. The sectors were selected using random number generation.

\subsection{Sample size determination}

According to Miaoulis and Michener (1976) there are three criteria that need to be specified in order to determine appropriate sample size. These criteria are the level of precision, the level of confidence or risk and the degree of variability in the attribute being measured.

Cochran (1977) specified a formula for calculating sample size which included all the three criteria as follows:

$$
\eta_{0}=\frac{Z^{2} * \mathrm{p} *(1-\mathrm{p})}{\mathrm{e}^{2}}
$$

Where;

$\eta \mathrm{o}=$ initial sample size, $\mathrm{z}=$ the abscissa of the normal curve that cuts off an area $\alpha$ at the tails (confidence level), $\mathrm{e}=$ acceptable sampling error (level of precision), $\mathrm{p}=$ the estimated proportion of an attribute that is present in the population.

The confidence level in this study was set as $\mathrm{z}=1.96$ (at $\alpha=0.025$ ), while the degree of precision $\mathrm{e}=0.05$ and the degree of variability were assumed to be maximum at $\mathrm{p}=0.05$.

The initial population size was then calculated using the formula above as follows:

$$
n_{0}=\frac{1.96^{2} * 0.5 *(1-0.05)}{0.05^{2}}=152
$$

This population size used to calculate initial sample size. According to Cochran (1977) when the sample size is greater than $5 \%$ of the population, then the adjusted formula of the presented sample can be used to calculate the adjusted sample size. The adjusted size of sample formula was expressed as;

$$
\eta_{1}=\frac{\eta_{0}}{1+\frac{\eta_{0}}{N}}
$$

Where $\eta 1=$ adjusted sample size, $\eta \mathrm{o}=$ initial sample size and $\mathrm{N}=$ Population size. The equation above was brought in to allow calculation the adjusted size of the study's sample where the values were taken to be $\eta 0=110$ and $\mathrm{N}=152$ and therefore the sample size used in this study was 110 .

\subsection{Sampling methods}

The sampling method firstly involved a purposive sampling Nyanza district on the relatively high prevalence of smallholder dairy farmer. The sectors selected are: Busoro, Kigoma, Mukingo, Cyabakamyi, Rwabicuma and Busasamana. The second stage involved determination of the proportions and number of respondents who would be drawn from each sector to constitute the required sample size. The following stage consisted of selection of the respondents by a simplified random selection of respondents from each sector based on the list of dairy farmers 
who produced milk in the previous milk production year June2016/17provided by the agricultural extensionist group leader at the village level.

\subsection{Data collection}

The primary data was collected with adoption of Participatory Rapid Appraisal (PRA) methods and semistructured questionnaire surveys. A pilot study was conducted in the study area to pre-test the questionnaires so as to check relevance of the questions before the survey. Data were collected through direct interview of respondents that was conducted by the principal researcher with assistance of data collection team and two local extension officers who were trained before data collection exercise.

\subsection{Determination of factors affecting technical efficiency}

As the dependent value in this objective comprised in the range of values between 0 and 1, the Tobit model was adopted and used in determination of factors affecting technical efficiency. The structural equation in the Tobit model is given as shown in equation (viii).

Where,

$$
T^{*}=X_{i} \gamma+\varepsilon_{i} \ldots \ldots \ldots \ldots(\text { viii })
$$

$$
\begin{array}{rll}
T^{*} & = & \begin{array}{l}
T^{*} \text { if } T^{*}>0 \\
0 \quad \text { if } T^{*} \leq 0
\end{array} \\
T^{*} & =\quad \text { Latent dependent variable } \\
X_{i} & =\quad \text { Factors affecting the dependent variable } \\
\gamma & = & \text { Coefficients of explanatory variables }
\end{array}
$$

Equation (viii) was expanded Similar to the study of to form equation (ix) and (x) for estimating factors influencing technical efficiency.

$$
\begin{aligned}
& T_{t . e}^{*}=X_{i t . e} \gamma+\varepsilon_{i t . e} \ldots \ldots \ldots \ldots(\mathrm{ix}) \\
& T_{\text {a.e }}^{*}=X_{\text {ia.e }} \gamma+\varepsilon_{\text {ia.e }} \ldots \ldots \ldots \ldots(\mathrm{x})
\end{aligned}
$$

Where,

t.e $=$ Represent Tobit regression for technical efficiency

In general, the expansion of Tobit regression model was similar to that of Masuku and Masuku (2014) is presented in equation (xi).

$$
T_{i}^{*}=\gamma_{0}+\gamma_{1} x_{1 i}+\gamma_{2} x_{2 i}+\gamma_{3} x_{3 i}+\gamma_{4} x_{4 i}(\mathrm{xi})
$$

\section{Results and discussions}

The TE in smallholder dairy farmers varies from $25 \%$ to $97 \%$ with average technical efficiency of $65 \%$. The result implies that $65 \%$ of potential output is being realized by the smallholder dairy farmers in Nyanza District. This finding is similar to the findings of Sharma and Singh (2011) in India. Moreover, the results conform to the findings of Thiam et al. (2001) who generalized that TE in smaller farmers in developing countries range from $17 \%$ to $100 \%$ with a mean of $68 \%$. The mean productivity of smallholders in Nyanza district indicated that there is a short fall inefficiency by $36 \%$ and the farmers can improve their milk production by $36 \%$ without requiring additional inputs and without the need for new technology. The least efficient farmer can improve by $48 \%$ to attain the efficiency level of the average smallholder dairy farmer. The technical efficiency scores in indicate that Mukingo has the highest mean technical efficiency of $75 \%$ while Rwabicuma sector has relatively lowest mean technical efficiency level of 53\%. There scores indicate that Mukingo sector has highest level of efficiency compared to other sectors may be due to its long experience in keeping dairy cows compared to other sectors. When technical efficiency is examined according to the herd size the results shows that smallholder dairy farmers with herd size of 1 and 2 cows, all have the same mean efficiency of $68 \%$ while smallholder dairy farmers with herd size of 3 and 4 cows have mean technical efficiency of $75 \%$ and $99 \%$ respectively. However, when correlation coefficient was analysed the results indicated the correlation coefficient of 0.034 . This value was not meaningful or significant at $5 \%$. This finding reveals that no significant linear association in combination or between herd size and the TE level of dairy farmer.

\subsection{Effects of Social Economic Factors on Technical Efficiency}

The model indicates that the gamma value of gamma is 0.99 . The hypothesis testing for the significance of the value of gamma was conducted using Likelihood Ratio test presented by equation 5 . The log likelihood function of the OLS was -17.86 while that of MLE of Stochastic production function was -4.16 . These values were used

to compute the LR using equation 5, whereby the calculated test statistic was 27.40 . The critical value for $x^{2}(0.05,7)$ from Palm et al. (1986) table of statistics is 11.91. Hence the hypothesis stating that there is absence of inefficiency effect from this model is confidently rejected. This result indicates that around $99 \%$ for the random disparity of the model is explained by technical inefficiency. The previous hypothesis (null) stating the non-stochasticity of 
technical inefficiency effects is also confidently rejected implying the appropriateness of the application of stochastic production frontier. The third null hypothesis stating that the inefficiency effect follows the half normal distribution is strongly rejected. Lastly the hypothesis which states that inefficiency effect is not influenced by social economic factors is confidently rejected at $5 \%$ of significance implying that social economic factors jointly influence inefficiency of smallholder dairy farmers.

\subsection{Socio-economic factors affecting technical efficiency of smallholder dairy production.}

From the findings the researcher founds that social-economic factors affect technical efficiency with majority agreeing that gender of the respondent. Age structure of the respondent, education level of the respondent, dairy farmers experience, household size of the respondents, herd size, use of skilled labour has great significant on the technical efficiency of small holder dairy production all affect the technical efficiency of smallholders' dairy production.

\subsection{Institutional factors affecting technical efficiency of smallholders' dairy production}

From the findings the researcher found that social-economic factors affects technical efficiency with majority agreeing that gender (being male or female) of the respondent, age structure of the respondent, education level of the respondent, dairy farmers experience, household size of the respondents, herd size, use of skilled labour affected significantly the technical efficiency in smallholder dairy production. This was indicated by $64.3 \%$ Male and $35.7 \%$ Female; $37.8 \%$ of the respondents were between $41-50,27.6 \%$ were between $31-40,24.5 \%$ between 21 - 30 and $10.2 \%$ above 50 years, $64.3 \%$ of the respondents was under O level education, $29.6 \%$ was A level education and $6.1 \%$ Bachelors and above education, $64.3 \%$ of the respondents were experienced for more than 5 years and above, $25.5 \%$ between $3-4$ years, $7.1 \%$ between $2-3$ years and $3.1 \%$ for a period between $1-2$ years, $36.3 \%$ of the respondents indicates that household size of the respondents ranged from $1-2$ people ; $21.8 \%$ had household hosting of 2-3 people; $10.9 \%$ had household hosting of 3-4 people; $30.9 \%$ had household hosting 5 people and above. The herd size results indicated that $31.8 \%$. of the respondents own $1-2$ dairy cattle, $45.4 \%$ own of 2-3 dairy cattle , $18.1 \%$ own 3-4 dairy cattle and 4.5\% own more than 5cows. The labour force results indicated that $72.7 \%$ of the respondents employs skilled labor while 27.3 doesn't employ skilled labor respectively.

\subsection{Smallholders dairy farmers technical efficiency}

The results indicated that extension service, feeds, labour, herd size, veterinary services and roughage are significant input variables at 5\% level for milk production. The input variable feed, labour, herd size and roughage have expected signs. The results also indicated that the null hypothesis $\mathrm{H} 0: \beta \mathrm{ij}=0$, which stated that Cobb-Douglas function presented an adequate representation of the function of production which was confidently rejected at 0.05 level of significance in favour of trans-log function.

The TE of smallholder dairy farmers ranges between $25 \%$ and $97 \%$; it had average (mean) TE of $65 \%$. An efficiency level of farmers is widely distributed with $62.8 \%$ having efficiency level above $61 \%$ while $37.5 \%$ have efficiency level below that.

The technical efficiency scores indicated that Mukingo has the highest mean technical efficiency of $75 \%$ while Rwabicuma sector has relatively lowest mean technical efficiency level of 53\%.

\section{Conclusion and recommendations}

In the findings it was established that socio-economic factors and institutional factors affects technical efficiency of smallholder dairy production.

The results of technical efficiency indicated that small holders on Nyanza county are moderately efficient.

The farmers in Nyanza county earn normal profit where the mean per cow in year is 119.39 USD. Socioeconomic factors and institutional factors should be improved in order the dairy farmers in Nyanza county can increase their efficiency. The farmers expenses on feeding and extension service can be decreased to improve on gross profit margin. This can be achieved by increasing farmers milk production through being efficient i.e cutting cost on extension service through preventive measures; Farmers to use new dairy technology to improve the level of efficiency.

Further researches are required to assess the innovation and allocative efficiency among smallholder dairy farmers; this will help policy and decision makers on appropriate support with both incentive and policy development.

\section{Statement of no competing interests}

We, the authors hereby declare that there are no competing interests in this research and publication.

\section{Acknowledgements}

This study was largely self-funded by the team of researcher from both Jomo Kenyatta University of Agriculture 
and Technology (JKUAT). However, the authors greatly acknowledge the support from the institutions for availing ample time to complete this research. The authors are very grateful to the local authorities and the farmers in Nyanza District for good collaboration.

\section{References}

Aigner, D.J, Lovell, A.K and Schimidt, P (1977). Formulation and Estimation of Stochastic Frontier Production Functions Model. Journal of Econometircs, 5, 21-38

B.B. Masuku and M.B. Masuku (2012). Technical and Allocative Efficiency of Smallholder Dairy Farmers in Swaziland. Journal of Economics and Sustainable Development. Vol.5, No.15 2014

Battese, G. and Coelli, T. (1995). A model for technical inefficiency effects in a stochastic frontier production function for panel data. Empirical Economics 20: 325 - 332.

Coelli, T.J.,Rao, D.S.P.,O’Donnell,C.J.,and Battese, G.E.(2005).An Introduction To Efficiency and Productivity Analysis. Spinger, second edition

Debreu, G.(1951). The coefficient of resource utilization. Econometrica, 19(3):273-292

Dlamini, S., Rugambisa, J.I, Masuku, M.B and Belelete, A (2010). Technical Efficeincy of the Small Scale Surgacane Farmers in Swaziland: A Case Study of Vuvulane and Big Bend Farmers. African Journal of Agriculture Research, 5 (9). 935-940.

Douglas, S. P., Craig, C. S., \& Nijssen, E. J. (2001). Integrating branding strategy across markets: Building international brand architecture. Journal of International Marketing, 9(2), 97-114.

FAO. (2015). Milk and Milk Products: Major Dairy Exporters and Importers. Food and Agriculture Organization of the United Nations.

Farrell, M.J.(1957).The measurement of productive efficiency. Journal of the Royal Statistical Society, 120(3):253-281.

Francesco Porcelli, Measurement of Technical Efficiency. A brief survey on parametric and non- parametric techniques, 2009.

Julius Kaia Kilungo, An economic analysis of smallholder dairy production in Kiambu district, Kenya, 1999

Land O’Lakes Inc. Baseline survey on Rwanda Dairy Competitiveness Program, 2014

Meeusen, W and Van den Broeck, J. (1977). Efficiency Estimation from Cobb-Douglas Production Function with Composed Error. International Economics Review.18, 435-444.

MINAGRI. (2013). National Dairy Strategy. Ministry of Agriculture and Animal Resources (MINAGRI), Republic of Rwanda, annual report 2012 